\title{
UNIVERSIDADES PÚBLICAS Y PRIVADAS: UN ENFOQUE TRIDIMENSIONAL
}

\author{
José Rigoberto Parada
}

Desde la aprobación en 1981 de la Ley Orgánica Constitucional de Enseñanza, en Chile se han usado diversos criterios para definir y denominar a los planteles que integran el sistema universitario chileno. Entre esas denominaciones las más comunes son universidad pública, privada, particular, estatal, compleja, simple, docente, de investigación, tradicional, del Consejo de Rectores. Toda clasificación tiene un objetivo operativo y la evidencia indica que en este caso ha sido determinar cómo asignar los recursos económicos del Estado. Surge, pues, la inquietud de cómo establecer una taxonomía que incorpore a las tres dimensiones del problema: tipo de propiedad, organización jurídica y productos y servicios que una universidad ofrece. Esto se plantea en este artículo, generando una clasificación que incluye simultáneamente estos tres aspectos, definiendo a su vez lo qué es una universidad pública y una universidad privada.

Palabras clave: universidad pública; universidad privada; corporación de derecho público; corporación de derecho privado; bienes públicos; bienes privados.

Recibido: mayo 2010. Aceptado: octubre 2010.

José Rigoberto Parada. Ingeniero comercial, Universidad de Concepción. Master en Administración y Dirección de Empresas, ESADE, Barcelona, España. Profesor e investigador de la Facultad de Ciencias Económicas y Administrativas de la Universidad de Concepción, Chile.

Estudios Públicos, 120 (primavera 2010). 


\section{Introducción}

$\mathrm{H}$

asta 1981 había sólo ocho universidades en Chile: dos de propiedad estatal, tres de propiedad de la Iglesia Católica y tres de propiedad privada sin fines de lucro. Tras la entrada en vigencia, en 1981, de la Ley Orgánica Constitucional de Enseñanza, comenzaron a crearse nuevos establecimientos universitarios y, en forma paralela, comenzaron a proliferar los criterios con los que se las debía definir y agrupar, principalmente para efectos de determinar los recursos que recibirían del Estado para su financiamiento.

Entre las categorías más habituales con que se ha agrupado a los planteles universitarios están las siguientes: universidades tradicionales (que reciben aportes directos del Estado), universidades derivadas (planteles originados esencialmente de la Universidad de Chile y Universidad Técnica del Estado, a partir de 1981), universidades privadas (creadas a partir del año 1981), universidades públicas (haciéndolas equivalentes a las de propiedad estatal), universidades del Consejo de Rectores. Por su parte, el directorio de universidades del Ministerio de Educación de Chile utiliza tres categorías: universidad estatal, universidad particular con aporte estatal y universidad privada.

Y si revisamos la literatura encontramos, por ejemplo, que la única variable considerada por Mönckeberg (2007, p. 576) para incluir un plantel en su listado de "universidades públicas" es la propiedad estatal. Luego clasifica como "universidades particulares" a planteles que pertenecen al Consejo de Rectores y que no son de propiedad estatal, y como "universidades privadas" a las generadas a partir de 1981, pero sin explicar cómo se discrimina entre una "privada" y una "particular". Krauskopf (1992, p. 25), a la inversa, denomina "universidades privadas" a las que Mönckeberg llama "universidades particulares", e incluye a su vez otras denominaciones como "universidad docente" y "universidad de investigación".

Por su parte, Brunner (1991, p. 24) establece una separación entre "universidades estatales" y "universidades privadas", desglosando a estas últimas en dos grupos: "universidades privadas antiguas" y "universidades privadas nuevas". El rector de la Universidad de Santiago, J. Zolezzi (2009, p. 11), a su vez, afirma que la "educación superior pública [...] es aquella que provee el Estado", y para hacer más intrincado el asunto, agrega que no hay incompatibilidad en que existan 
"universidades públicas y tradicionales de propiedad privada [y que] su coexistencia debe darse en igualdad de condiciones".

También se ha propuesto el concepto de "complejidad" para clasificar a las universidades. Merino (2004) ha planteado que en el sistema universitario chileno "coexisten universidades públicas con universidades privadas; universidades simples, esto es, que cultivan prioritariamente la docencia como función universitaria, con universidades complejas, que cultivan además la investigación, la creación artística y extensión". Este criterio de complejidad que da origen a la categoría de "universidad compleja", que también la emplea Beyer (2009), se basa en los productos y servicios que ofrece una universidad y no en si el establecimiento es de propiedad fiscal o privada.

Por último, la OCDE, en su informe "La Educación Superior en Chile" (2009, p. 35), clasifica a los planteles chilenos en dos categorías: "universidades tradicionales [que] reciben fondos públicos directos" y "universidades privadas [...] creadas por el sector privado". Respecto del financiamiento de los planteles, en p. 248 se hace explícito la homologación entre universidad pública y universidad estatal, pues bajo el título de "Diversificación de recursos en universidades públicas" se señala que las "universidades estatales" — haciéndolas equivalentes a las universidades públicas - deben buscar recursos adicionales a los fondos fiscales para financiarse. Para que no quede duda sobre dicha interpretación, en el mismo párrafo se compara una universidad de propiedad estatal con una organizada como corporación de derecho privado ( $\sin$ fines de lucro), reclamando por que la segunda recibiría más recursos del Estado que la primera. En este informe, en efecto, es donde mejor se expresa la visión unidimensional, basada sólo en la variable de la "propiedad", para asignar los recursos económicos del Estado. El informe tampoco establece alguna relación entre la asignación de recursos públicos con los productos y servicios que ofrece cada universidad, lo cual, desde un punto de vista económico, constituye una importante deficiencia conceptual que afecta la distribución eficiente y eficaz de los recursos públicos.

Las preguntas que nos hacemos, entonces, son: ¿debe una universidad ser financiada totalmente por el fisco por el sólo hecho de ser propiedad del Estado? ¿Puede una universidad organizada jurídicamente como corporación de derecho privado (sin fines de lucro) recibir recursos del Estado para su funcionamiento? 
El objetivo de este artículo es presentar una metodología conceptual que permita asignar los recursos del Estado en forma eficiente y eficaz, para lo cual se propone distinguir entre los distintos planteles universitarios considerando simultáneamente tres aspectos fundamentales: propiedad de la universidad, organización jurídica de ella y el tipo de bienes o productos que ofrece. Como subproducto del método propuesto, se plantean a su vez otras definiciones de universidades, tales como "universidad docente", "universidad de investigación" y "universidades semipúblicas o semiprivadas".

\section{Bases conceptuales para una clasificación de las universidades chilenas}

Considerar la "propiedad" como criterio central o único para asignar los recursos de Estado es equivocado. Es más, en vista de los problemas de mercado que presenta el sistema universitario chileno, no sólo interesa asignar en forma eficiente los recursos fiscales, sino también regular de manera adecuada el sistema universitario. Desde una óptica económica, en efecto, no se estarían asignando bien los recursos fiscales si una universidad de propiedad estatal que se dedicase a proveer bienes privados, por los cuales podría cobrar un arancel elevado y superior al del resto del sistema, recibiera del fisco todo el financiamiento que necesita para su operación. En el otro extremo, tampoco se le deberían negar recursos estatales a una universidad organizada como corporación de derecho privado, sin fines de lucro, que sólo produce bienes públicos, tales como investigación básica o extensión universitaria gratis.

Por lo tanto, es un error considerar que la universidad de propiedad estatal debería, por ese solo antecedente, recibir más aportes estatales, independientemente de los productos que entregue o las tareas que desempeñe. Con el fin de resolver el problema de cómo asignar los recursos del Estado, es necesario establecer entonces, sin caer en discrecionalidades, una clasificación de los planteles universitarios chilenos que tome en cuenta las distintas variables o dimensiones envueltas.

La primera a considerar es la propiedad de la universidad. La segunda es jurídica, esto es, cómo está legalmente constituida la universidad. La tercera proviene del ámbito de la economía y se refiere a los productos que la universidad ofrece, pues, desde el punto de vista de la eficiencia en la asignación de los recursos, no se puede operar como si 
los productos académicos fuesen irrelevantes, ni tampoco se puede proceder a asignar recursos fiscales en ausencia de una calificación previa de esos productos como bienes públicos o privados.

Esta aproximación tridimensional (véase Fig. $\mathrm{N}^{\circ} 1$ ) permitiría distinguir entre universidades públicas puras, universidades privadas puras y mixtas (semipúblicas o semiprivadas). En un extremo hablaríamos de universidad pública cuando simultáneamente se trata de un plantel de propiedad estatal, con personalidad jurídica pública y que, desde un punto de vista económico, sólo ofrece bienes públicos. Pero también podría darse una universidad privada que sólo ofrece bienes públicos. Y esto es así porque las universidades no ofrecen un solo tipo de bienes. Entre los productos que esencialmente ofrece una universidad están los grados académicos, títulos profesionales, investigación básica, investigación aplicada y desarrollo de experimentos, asistencia técnica, bienes de esparcimiento a la población (campus-parques abiertos, orquestas sinfónicas, museos de arte y científicos, jornadas artísticas y culturales, etc.) y otros. Pues bien, cada uno de estos productos tiene características particulares, por lo que no son todos ellos necesariamente idénticos ni homologables entre sí. En consecuencia, las universidades pueden presentar características "públicas" y "privadas" según los distintos productos que ofrecen.

FIGURA N ${ }^{\circ}$ 1: $\quad$ CRITERIOS BASE PARA DEFINICIÓN DE UNA UNIVERSIDAD

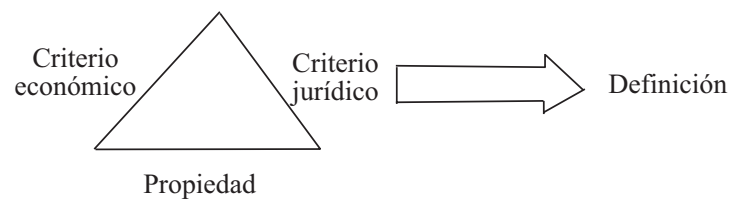

Cuando se consideran las tres aristas del problema, surgen entonces múltiples posibilidades, como se aprecia en la Tabla $\mathrm{N}^{\mathrm{o}} 2$ que presenta, para efectos de ilustración, una situación simplificada en la que sólo se ofrecen dos tipos de bienes: títulos y grados académicos e investigación, ya sea como bienes públicos o privados. Supongamos, a modo de ejemplo, una universidad cuya propiedad es estatal, que está 


\begin{tabular}{|c|c|c|c|c|c|c|c|c|c|}
\hline \multirow{2}{*}{\multicolumn{2}{|c|}{$\begin{array}{l}\text { Organización jurídica } \\
\text { Bienes económicos }\end{array}$}} & \multicolumn{4}{|c|}{ Corporación de derecho público } & \multicolumn{4}{|c|}{ Corporación de derecho privado } \\
\hline & & \multicolumn{2}{|c|}{ Bienes públicos } & \multicolumn{2}{|c|}{ Bienes privados } & \multicolumn{2}{|c|}{ Bienes públicos } & \multicolumn{2}{|c|}{ Bienes privados } \\
\hline \multicolumn{2}{|c|}{ Productos } & Títulos & Investi- & Títulos & Investi- & Títulos & Investi- & Títulos & Investi- \\
\hline \multirow{2}{*}{ 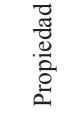 } & Privada & & & & & & & & 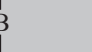 \\
\hline & Estatal & & & & & & & & \\
\hline
\end{tabular}

organizada jurídicamente como corporación de derecho público y que ofrece los dos productos (títulos y grados académicos e investigación). En este esquema, dicha universidad se podría ubicar en cualquiera de los ocho cuadrantes de la primera fila (de abajo hacia arriba). Ahora, si todos sus bienes fueran económicamente bienes públicos (sector " $\mathrm{A}$ " oscurecido de la tabla), entonces sería una universidad pública pura. En el otro lado, una universidad de propiedad privada, organizada jurídicamente como corporación de derecho privado y que sólo ofrece bienes privados (tanto títulos y grados como investigación) sería una universidad privada pura (sector "B" oscurecido de la tabla).

A continuación nos referiremos a cada una de las tres dimensiones.

\section{1. "Propiedad" de las universidades}

Uno de los pilares básicos para clasificar las universidades en Chile es la estructura de propiedad de sus activos y patrimonio, la cual condiciona su existencia económica y financiera, así como sus órganos de gobierno y la fijación de políticas y estrategias para su permanencia en el tiempo. Se distinguirán aquí dos tipos de propiedad: 1) estatal y 2) no estatal. Esta segunda agrupación puede tener matices, pues finalmente tendrá implicación aquí la forma jurídica que adopte la universidad. Así, su propiedad puede ser privada y estar organizada como una corporación o fundación, o simplemente ser de propiedad de un grupo de personas organizadas en otras entidades, sean instituciones religiosas, organizaciones políticas, organizaciones no religiosas pero "espirituales", o simplemente personas naturales. 
Conforme a lo anterior, las universidades chilenas se podrían agrupar en las siguientes categorías:
A) Universidades de propiedad estatal (16 universidades):
Universidad Arturo Prat
Universidad de Tarapacá
Universidad de Antofagasta
Universidad de Atacama
Universidad de La Serena
Universidad de Valparaíso
Universidad de Playa Ancha de Ciencias de la Educación
Universidad de Santiago
Universidad de Chile
Universidad Tecnológica Metropolitana
Universidad Metropolitana de Ciencias de la Educación
Universidad de Talca
Universidad del Biobío
Universidad de La Frontera
Universidad de Los Lagos
Universidad de Magallanes.

B) Universidades de propiedad no estatal, las que a su vez podrían subdividirse en tres clases:

B.1) Universidades de propiedad de organismos religiosos (11 universidades):

B.1.i) De la Iglesia Católica:

Universidad Católica del Norte

Pontificia Universidad Católica de Valparaíso

Pontificia Universidad Católica de Chile

Universidad Católica del Maule

Universidad Católica de la Santísima Concepción

Universidad Católica de Temuco.

B.1.ii) Hay otras universidades católicas que no son de propiedad de la Iglesia Católica sino que están regidas por corporaciones o fundaciones asociadas a congregaciones católicas. Éstas son: 
Universidad Alberto Hurtado (Compañía de Jesús)

Universidad Cardenal Raúl Silva Henríquez (Congregación Salesiana)

Universidad de los Andes (Opus Dei)

Universidad Finis Terrae (Legionarios de Cristo).

También está la Universidad Adventista de Chile, cuya propietaria es la Corporación Iglesia de los Adventistas del Séptimo Día.

La Pontificia Universidad Católica de Chile fue creada el año 1888 y la Pontificia Universidad Católica de Valparaíso en 1928. Las restantes se crearon a partir del año 1991.

B.2) Universidades de propiedad de una corporación o fundación sin fines de lucro (3 universidades):

Universidad de Concepción

Universidad Federico Santa María

Universidad Austral.

Estas universidades fueron creadas en los años 1919, 1935 y 1954, respectivamente

B.3) Universidades chilenas de grupos u organizaciones privadas (31 universidades).

Universidad Academia de Humanismo Cristiano

Universidad Adolfo Ibáñez

Universidad Autónoma de Chile

Universidad Bernardo O’Higgins

Universidad Bolivariana

Universidad Central de Chile

Universidad Chileno-Británica de Cultura

Universidad de Aconcagua

Universidad de Artes, Ciencias y Comunicaciones (Uniacc)

Universidad de Artes y Ciencias Sociales (Arcis)

Universidad de Ciencias de la Informática (Ucinf)

Universidad de las Américas

Universidad de Rancagua

Universidad de Viña del Mar

Universidad del Desarrollo 


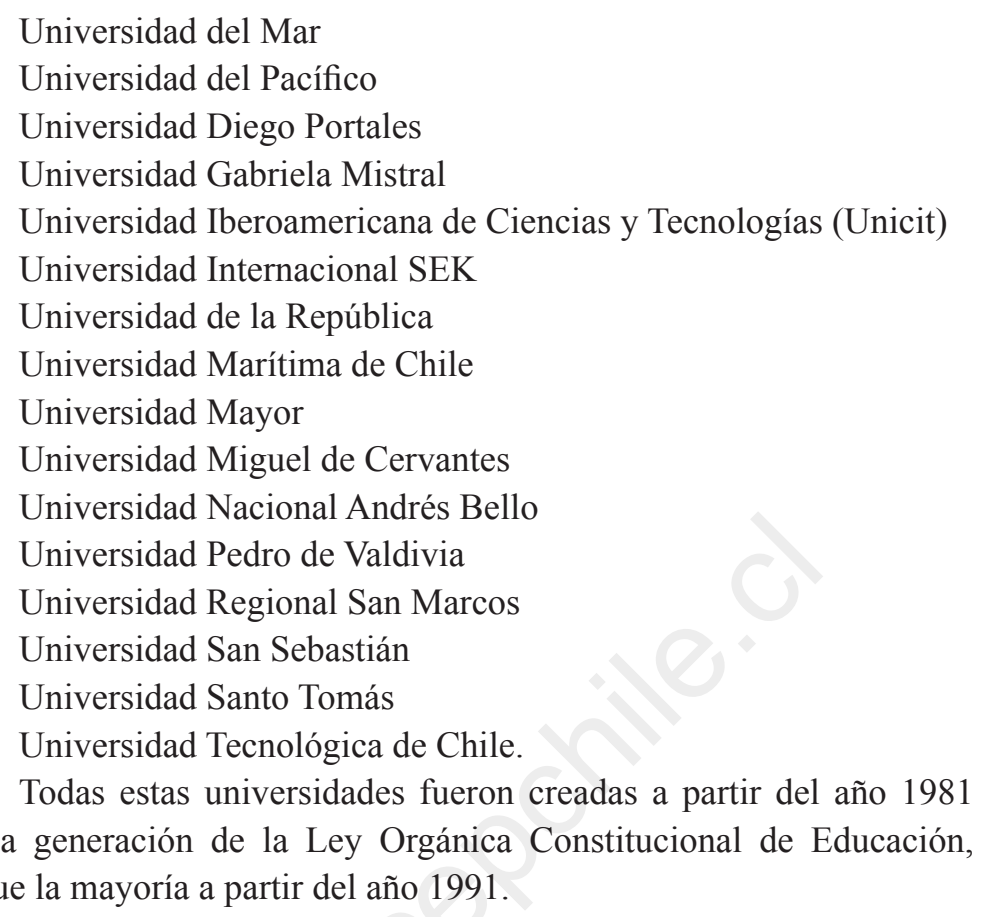

\subsection{Organización jurídica de las universidades}

Conforme al Código Civil chileno, las universidades pueden adoptar la personalidad jurídica de derecho público o de derecho privado. El Código Civil en su Título XXXIII, artículos 545-564, explicita sus características. De igual forma, el Reglamento sobre Concesión de Personalidades Jurídicas a Corporaciones y Fundaciones (Diario Oficial $\left.\mathrm{N}^{\mathrm{o}} 30.319,20.3 .1979\right)$ aclara estos conceptos.

Respecto a las entidades que pueden adoptar la personalidad de derecho público, el Código Civil (Art. 547, inciso 2) incluye explícitamente a las corporaciones o fundaciones como la nación, el fisco, las municipalidades, las iglesias, las comunidades religiosas y los establecimientos que se costean con fondos del erario. En el caso de las universidades, aquí caben las universidades de propiedad estatal, a pesar de ser organizaciones con autonomía y con cierta independencia para cumplir con sus tareas. También caben aquí las organizaciones asociadas a las iglesias, dentro de las cuales están sus universidades. 
En cuanto a las entidades que pueden constituirse como personas de derecho privado, están las corporaciones de derecho privado y las fundaciones. Según Alessandri, Somarriva y Vodanovic (2005, p. 537), el texto de las disposiciones del Título XXXIII del libro primero del Código Civil sólo menciona que las corporaciones son asociaciones que no persiguen fines de lucro. En general, las corporaciones de derecho privado pueden tener fin de lucro, pero no es el caso chileno, pues las que persiguen fin de lucro se denominan sociedades y son regidas por otros títulos del Código Civil (Título XXVIII, respecto a sociedades) o por el Código de Comercio. Para el caso que aquí interesa, también es relevante distinguir qué tipo de organización tienen las universidades que no están explicitadas en el Código Civil como corporaciones de derecho privado, sin fin de lucro, tales como la Universidad de Concepción y la Universidad Federico Santa María.

En las corporaciones de derecho privado, según el Reglamento sobre Concesión de Personalidad Jurídica, hay dos tipos de organizaciones: corporación y fundación, ambas con diferencias de matices. Así, en el caso de una corporación sus miembros son sus integrantes y en las fundaciones sus miembros tienen el carácter de destinatarios; la corporación es una asociación de personas y la fundación es un patrimonio donado por alguien para un fin determinado. También hay diferencias respecto a quién otorga el patrimonio: en la fundación lo entrega un fundador donante y en el caso de la corporación su patrimonio lo forman sus socios. Sin embargo, lo relevante en ambas formas es que son organizaciones sin fines de lucro, lo que para el caso de las universidades chilenas tiene una importancia central, pues por ley ninguna universidad puede tener como objetivo el lucro.

Este último aspecto es uno de los mayores problemas del sistema universitario chileno, pues hay universidades que han ido creando organizaciones paralelas a ellas para encubrir el lucro. Una práctica de encubrimiento es la separación legal entre la universidad y los edificios que ésta ocupa, creándose dos organizaciones paralelas, donde la primera es un ente que entrega educación, investigación y extensión, y la segunda, propietaria de los edificios, arrienda las instalaciones a la primera para que ésta cumpla su labor. Así, a través de empresas inmobiliarias, creadas por los mismos dueños de la universidad, éstos se hacen propietarios de los edificios, los que luego arriendan a las universidades. Esta figura permite que las universidades traspasen "beneficios" o "lucro" a 
las inmobiliarias, y como los dueños de la inmobiliaria son los mismos dueños de la universidad, se genera lucro a través del sistema universitario. Mönckeberg (2007) muestra algunas prácticas de universidades chilenas que ponen en riesgo el principio puro de ser organizaciones "sin fin de lucro".

En general, las universidades de propiedad estatal chilena se organizan como corporaciones de derecho público, al igual que las universidades de propiedad de la Iglesia Católica. Todas las restantes se organizan como corporación de derecho privado que, como ya se señaló, son organizaciones que, según el Código Civil y también estipulado por la Ley Orgánica Constitucional de Educación, no persiguen "fines de lucro".

\subsection{Bienes y servicios de las universidades como bienes públicos o bienes privados}

\subsubsection{Conceptualización económica de bienes públicos y privados}

Samuelson y Nordhaus (1996, p. 356) señalan que "los bienes públicos son aquellos cuyos beneficios se extienden de manera indivisible a toda la comunidad, independientemente de que los individuos deseen o no comprarlos. Los bienes privados, por el contrario, son aquellos que pueden dividirse y suministrarse por separado a diferentes individuos sin que produzcan beneficios ni costos externos a otros. La intervención del Estado suele ser necesaria para suministrar eficientemente los bienes públicos, mientras que los bienes privados pueden ser asignados eficientemente por los mercados". De acuerdo con esta concepción, los bienes públicos están disponibles para la toda la sociedad y ella se beneficia del conjunto de bienes, por ejemplo: defensa nacional, educación básica y media, investigación básica, entre otros. Asimismo, se considera que los bienes públicos no son suministrados eficientemente por el mercado.

Nicholson (2004, pp. 679-680) plantea una definición más operativa basándose en dos características de los bienes públicos que se refieren a la no exclusión y la no rivalidad en el consumo. Señala que "un bien es excluyente si resulta relativamente fácil, una vez producido el bien, excluir a otros individuos de su beneficio. Un bien es no excluyente cuando es imposible, o muy caro, excluir a otros individuos 


\begin{tabular}{|c|c|c|c|}
\hline & \multicolumn{2}{|c|}{ Exclusión } \\
\hline & & Sí & No \\
\hline \multirow{2}{*}{ 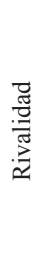 } & Sí & $\begin{array}{l}\text { Bienes privados: } \\
\text { Alimento, vestuario, casas, } \\
\text { automóviles, entre otros. }\end{array}$ & $\begin{array}{l}\text { Bienes comunes: } \\
\text { Aire y agua sin contaminar, } \\
\text { bancos de pesca, entre otros. }\end{array}$ \\
\hline & No & $\begin{array}{l}\text { Públicos incompletos: } \\
\text { Electricidad, puentes, TV por cable, } \\
\text { carreteras con peaje, entre otros }\end{array}$ & $\begin{array}{c}\text { Bienes públicos: } \\
\text { Defensa nacional, aire, agua, } \\
\text { investigación básica, entre otros }\end{array}$ \\
\hline
\end{tabular}

del beneficio del bien". Por bienes no rivales señala que "un bien es no rival si el consumo de unidades adicionales del bien implica un costo marginal social nulo de la producción". Esta definición es más operativa y se muestra en la Tabla $\mathrm{N}^{\mathrm{o}} 2$, también basada y adaptada de Nicholson (p. 681).

En general, el Estado interviene en la producción de bienes públicos por varias razones, entre otras: cuando al sector privado no le interesa participar en la producción de esos bienes; cuando el bien público es ofrecido por monopolios debido a que existe información incompleta para los participantes del mercado; cuando se trata de asuntos como defensa nacional, y también cuando asumen gobiernos con enfoques intervencionistas en el mercado.

A partir del enfoque matricial presentado en la Tabla $\mathrm{N}^{\circ} 2$ se pueden analizar los diferentes productos ofrecidos por las universidades y abordar así la tercera dimensión relevante para generar una definición de lo que diferencia una universidad pública de una universidad privada.

\subsubsection{Productos y bienes universitarios}

Éstos se pueden agrupar en tres rubros:

a) Títulos profesionales y grados académicos.

Los grados académicos son: licenciatura, magíster y doctorado.

Los títulos profesionales, según la Ley Orgánica Constitucional de Educación, son diecisiete, pero las universidades los han diversificado aún más. 
b) Investigación y desarrollo (IyD).

La definición de IyD del "Manual de Frascati" de la OCDE incluye investigación básica, investigación aplicada y desarrollo de experimentos. Estos dos últimos dan origen a la llamada "invención, innovación y difusión".

c) Extensión universitaria.

La extensión universitaria incluye una variada gama de servicios y productos, entre ellos: museos artísticos, museos científicos, orquestas de cámara, sinfónicas o filarmónicas, campus y parques abiertos a la comunidad, jornadas de arte y científicas, medios de difusión universitarios comerciales y no comerciales (radiodifusoras, canales de televisión y diarios), jornadas deportivas, clubes deportivos y de entretención, servicios a la comunidad (asesorías a empresas y organismos estatales), atenciones médicas y dentales, entre otros.

Los bienes incluidos en estos tres grupos tienen características particulares, por lo que deben ser analizados por separado para determinar si deben ser calificados como bienes públicos o privados.

a) Títulos profesionales y grados académicos

\section{a.1) Títulos profesionales}

En el caso de los títulos profesionales (que están explicitados en la legislación chilena) todo indica que en su mayoría son bienes privados, ya sea, en algunos casos, por las características mismas de las profesiones liberales, o porque el ejercicio profesional se desarrolla en forma "dependiente", con "exclusividad y rivalidad", como se explicará a continuación.

En efecto, los profesionales titulados en una universidad pueden trabajar como dependientes, esto es, ser contratados por un sueldo, por una jornada de trabajo completa en un organismo público o privado. En cualquiera de los dos casos, en términos prácticos, debido a los límites de la jornada de trabajo, esto implica que, cualquiera sea la organización que contrata al profesional, éste pasa a desempeñarse en forma exclusiva para esa entidad, y por tanto se excluye a otra organización de contratarlo. Por esta razón se dice también que existe "rivalidad" entre las organizaciones, pues la organización que contrata a ese profesional entra en rivalidad con las otras organizaciones que quisieran contratarlo.

Ya que los distintos sectores de la economía contratan tanto mano de obra como profesionales, y normalmente lo hacen con exclusividad, 
ello indica que los títulos profesionales pueden ser considerados bienes privados, desde el punto de vista tanto del que posee el título profesional como de quien contrata los servicios del profesional. Así, pues, si los profesionales universitarios son contratados con "exclusividad" y con "rivalidad", entonces el título profesional presenta las características de un bien privado.

Sin embargo, hay que establecer algunos matices, como en el caso de profesionales de la salud y la educación, que se desempeñan en áreas que tienen ciertas características de bienes públicos, lo que llevaría a que el Estado tenga participación en su promoción ya sea como regulador o como financista de una parte de los costos de producción de este tipo de profesional.

Y también hay otros "productos" universitarios que, aun cuando son poco demandados en el mercado de trabajo, tienen características de bienes públicos porque son necesarios desde un punto de vista del desarrollo social y producen una extrernalidad positiva. No todas las universidades ofrecen estos "productos", pues, como ya se señaló, tienen baja demanda, pero alguien debe ocuparse de su desarrollo. Ejemplos de este tipo de formación profesional son las ciencias básicas, filosofía, macroeconomía y algunas especialidades como las pedagogías en idiomas extranjeros como el francés, alemán, chino mandarín, japonés, entre otros. Este tipo de producto es ofrecido por muy pocas universidades chilenas ya sean de propiedad estatal o de propiedad no estatal.

\section{a.2) Grados académicos}

Desde el punto de vista económico, el caso de los grados académicos no es equivalente al del título profesional. A diferencia de un título profesional, por ejemplo, el primer grado académico de pregrado (la licenciatura) normalmente no tiene gran demanda laboral en comparación con los títulos profesionales que están señalados en la Ley Orgánica Constitucional de Enseñanza, ya que en la práctica sólo es un requisito para cursar el grado siguiente, de magíster. Por otro lado, en todos los programas de estudio que conducen a un título profesional, el grado de licenciatura es previo a la obtención del título profesional. Así, en estricto rigor, este producto no presenta los rasgos de "exclusión" y "rivalidad" en el mercado que caracterizan a los bienes privados, por lo que se asemeja más a un bien público. 
Con todo, los rasgos de bien público de los grados académicos se hacen más evidentes en algunos grados de magíster y, en especial, de doctor que son poco demandados en el mercado y sin embargo benefician a la sociedad en su conjunto. Pero esto requiere de un cuidadoso análisis conceptual, pues al ser productos relacionados con la investigación básica pueden ser financiados a través de esta vía. Esto es lo que sucede actualmente en las universidades chilenas que dictan posgrados. Por ejemplo, aun cuando un doctor en filosofía moral, o un doctor en física cuántica, u otros, sean poco demandados en el mercado laboral, la sociedad en su conjunto debe impulsar este tipo de programas de estudio que el sector privado probablemente no producirá. Estos dos casos de doctorados son ejemplos de productos que se acercan más a ser bienes públicos. Pero hay otros tipos de doctorados que pueden reunir características de bienes privados, lo que requiere de un estudio conceptual cuidadoso de cada producto ofrecido.

Un caso aparte son los posgrados demandados por la empresa, tales como el magíster en administración, que sí presentan las características de bienes privados.

Según datos de la Academia Chilena de Ciencias, y explicitados en el Informe de "Educación Superior en Chile" de la OCDE (2009), el año 2004 únicamente ocho universidades graduaron doctorados, y el $80 \%$ de esas graduaciones tuvieron lugar en sólo tres universidades (Universidad de Chile, P. Universidad Católica de Chile y Universidad de Concepción). Por otro lado, catorce universidades, todas pertenecientes al Consejo de Rectores de las Universidades Chilenas, tenían programas de doctorados. Pero el $68 \%$ de estos programas se concentra en sólo cuatro universidades (Universidad de Chile, P. Universidad Católica de Chile, Universidad de Concepción y Universidad de Santiago). Respecto al número de estudiantes matriculados en programas de doctorado, según datos del CRUCH (Consejo de Rectores) en su Anuario Estadístico, en el año 2006 el 70\% se concentra en las tres primeras universidades mencionadas; respecto a programas acreditados el año 2007 por la CONAP (Comisión Nacional de Acreditación de Postgrado), el $63 \%$ de los programas acreditados se concentra en sólo tres universidades, según datos de CSE (Bases de Datos históricos del Consejo de Educación Superior de las Instituciones de Educación Superior). Estos datos indican que estos bienes públicos son ofrecidos únicamente por 
muy pocas universidades y se encuentran altamente concentrados en tres o cuatro de ellas, independientemente de su propiedad y de la organización jurídica de los planteles. En resumen, no más del 8\% de las universidades chilenas ofrece bienes públicos como programas de posdoctorados.

b) Investigación y desarrollo (I\&D)

\section{b.1) Investigación básica}

La investigación básica es uno de los ejemplos más citados de un bien público. Una investigación sobre el genoma, por ejemplo, beneficia a toda la comunidad y sus resultados pueden ser publicados para provecho de toda la sociedad; en su consumo, entonces, no hay exclusión ni tampoco rivalidad. Un subproducto de la investigación básica es aquel relacionado con la difusión, tales como revistas científicas y libros. Normalmente la investigación básica no es, en caso alguno, un bien privado, salvo aquella investigación efectuada por gobiernos y que se mantiene en reserva por razones estratégicas de defensa, o de futuras explotaciones sujetas al resultado de esta investigación.

Para medir la incidencia de la investigación básica en la universidad chilena se pueden considerar los fondos obtenidos por cada universidad en su postulación a fondos competitivos para financiar investigación básica a través del Fondo para el Desarrollo de la Investigación Científica y Tecnológica (Fondecyt). Para el período 2000-2005, según datos del Informe de "La Educación Superior en Chile" (2009, p. 222), tres universidades concentran el $70 \%$ de dichos fondos (Universidad de Chile, P. Universidad Católica de Chile y Universidad de Concepción). El 28\% restante lo obtienen las demás universidades del Consejo de Rectores de Universidades Chilenas. Así pues, tomando como proxy de la investigación básica la distribución de estos fondos, se puede ver que sólo unas pocas universidades realizan investigación como un bien público. Estas cifras tampoco cambian si se toma como proxy de investigación básica el número de publicaciones en revistas científicas que originan los proyectos de investigación, pues nuevamente, en el período 2001-2003, cuatro universidades publican el $80 \%$ de todas las publicaciones nacionales (Universidad de Chile, P. Universidad Católica de Chile, Universidad de Concepción y Universidad de Santiago); el resto es publicado por universidades pertenecientes al Consejo de Rectores. 
Se concluye, pues, que la característica de bien público de la investigación básica es independiente de la propiedad y del régimen jurídico que la rige.

También está el caso de investigación básica que es encargada y contratada a las universidades por alguna empresa usuaria. Desde el punto de vista de bienes públicos y privados, esta investigación tendría el mismo carácter que la investigación aplicada que se analizará a continuación.

\section{b.2) Investigación aplicada y desarrollo de experimento}

Hay universidades que realizan esta segunda fase de la investigación, la que puede ser exclusiva y por tanto vendida a industrias. Si ocurre esto último, se trata de un "producto" que tiene características de bien privado, pues al ser vendido implica exclusión y rivalidad, características de un bien privado. En caso contrario, cuando la investigación aplicada sigue siendo comunicada a la sociedad y no es "apropiable", entonces es un bien público. Lo mismo es válido para la invención, innovación y difusión del conocimiento, que pueden tener características ya sea de bien público o bien privado, dependiendo del tipo de producto que se esté distribuyendo.

\section{c) Extensión universitaria}

Bajo esta denominación se encuentra un conjunto de productos y servicios universitarios que pueden presentar características ya sea de bien público o bien privado. La orquesta sinfónica de una universidad puede tener más características de bien público cuando, por ejemplo, presenta su repertorio musical en locales abiertos y en diferentes ciudades. Y puede ser un bien privado cuando sólo hace presentaciones reducidas en lugares con límite de capacidad y cobrando precios de mercado equivalentes a los de los espectáculos competitivos. Esto nos indica que para cualquier producto de extensión universitaria hay que hacer un análisis particular para definir si es un bien público o un bien privado.

Otro ejemplo de bien público son los museos de arte, abiertos a la comunidad durante toda la semana y gratuitos para sus visitantes. También los barrios universitarios (campus-parque) abiertos a la comunidad, equivalentes a una plaza pública cualquiera, pero financiados por la universidad. 


\section{Una taxonomía general de las universidades}

Una clasificación general de las universidades requiere definir un portafolio de los productos y servicios que ellas ofrecen para determinar ciertos rangos mínimos que se deben cumplir bajo los tres conceptos generales de títulos y grados académicos, investigación y desarrollo y extensión universitaria. Definidos estos mínimos, deben considerarse las diferentes combinaciones posibles para definir claramente lo que es universidad pública y universidad privada, lo que permitirá asignar en forma eficiente los recursos económicos del Estado.

La Figura $\mathrm{N}^{\circ} 2$ presenta la secuencia de análisis que incluye las tres dimensiones del problema. El primer nivel de análisis es la propiedad de la universidad, que puede ser estatal o no estatal; el segundo nivel muestra que cualquiera sea su propiedad, la universidad puede estar indistintamente organizada como corporación de derecho público o corporación de derecho privado. El tercer nivel indica que cualquiera sea su propiedad y organización jurídica, las universidades ofrecen tres productos o servicios globales: títulos profesionales y grados académicos, investigación básica y aplicada, y extensión universitaria. La última etapa de análisis consiste en determinar si cada uno de los productos que se ofrecen en docencia, investigación y extensión es, desde el punto de vista económico, bien público o bien privado, o si hay algunos con características más complejas que requieren definiciones más precisas.

De este análisis secuencial — propiedad-estructura jurídica-análisis económico- se obtienen cuarenta posibles escenarios, en base a los cuales se podría agrupar a las universidades en categorías homogéneas y no discrecionales. Por ejemplo, una situación extrema sería la de una universidad de propiedad no estatal, organizada como corporación de derecho privado (por tanto, sin fines de lucro) que ofrece cabalmente los tres productos centrales, pero que sólo corresponderían a bienes públicos. Esta situación estaría indicada en la última columna de la Figura $\mathrm{N}^{\mathrm{o}} 2$ por los puntos (11), (13), (15), (17) y (19). Esta universidad sería semejante a una universidad de propiedad estatal, organizada como corporación de derecho público y que también ofrece en forma íntegra los tres productos, los que son sólo bienes públicos, la que estaría representada en el gráfico por los puntos (1), (3), (5), (7) y (9). Observando el portafolio de productos y servicios que actualmente ofrecen las universidades chilenas, tentativamente se podría afirmar que en esas categorías 
FIGURA N ${ }^{\circ}$ 2: $\quad$ DIAGRAMA DE ANÁLISIS DE UNIVERSIDADES: PROPIEDAD, ESTRUCTURA JURÍDICA Y BIENES ECONÓMICOS

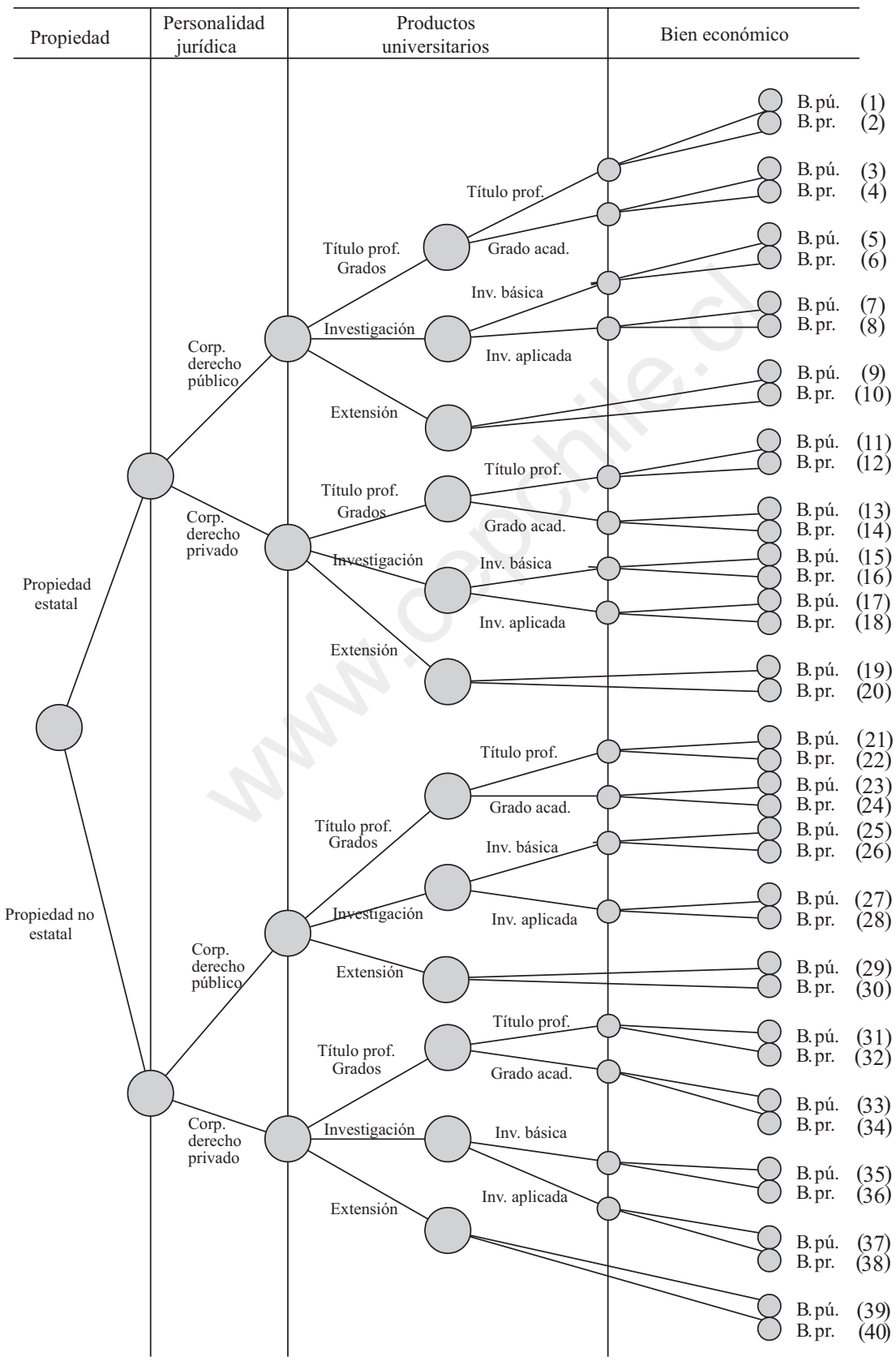


pueden calificarse muy pocas universidades, aunque ello requiere precisar más los atributos mínimos que debe tener cada agrupación. De esta manera, se pueden obtener diferentes combinaciones que permitirían tener agrupaciones homogéneas para efectos de asignación de recursos. A su vez, dicho esquema hace posible distinguir entre universidades semipúblicas, universidades docentes y universidades de investigación. Las definiciones que se deducen son las siguientes:

a) Universidades completas. Son aquellas que ofrecen una amplia gama de productos y servicios, en los tres niveles (títulos y grados, investigación y desarrollo, y extensión universitaria). Éstas se pueden agrupar en:

a.1) Universidades públicas puras. Son aquellas que ofrecen una amplia posibilidad de productos y servicios universitarios en los tres niveles, pero en todos ellos hay bienes económicos públicos. Pueden también ofrecer bienes privados (véase Tabla $\mathrm{N}^{\circ} 3$ ).

a.2) Universidades privadas puras. Son aquellas que ofrecen una amplia posibilidad de productos y servicios universitarios en los tres niveles, pero en todos ellos hay bienes privados. Pueden también ofrecer bienes públicos (véase Tabla $\mathrm{N}^{\circ} 4$ ).

a.3) Universidades semipúblicas. Son universidades que en los tres rubros ofrecen más bienes públicos que privados.

TABLA N ${ }^{\circ}$ 3: $\quad$ UNIVERSIDAD COMPLETA PÚBLICA PURA

\begin{tabular}{|c|c|c|c|c|c|c|}
\hline \multirow[b]{2}{*}{ Propiedad } & \multirow[b]{2}{*}{$\begin{array}{l}\text { Régimen } \\
\text { jurídico }\end{array}$} & \multicolumn{5}{|c|}{ Bienes económicos públicos o privados } \\
\hline & & $\begin{array}{c}\text { Título } \\
\text { profesional }\end{array}$ & $\begin{array}{c}\text { Grados } \\
\text { académicos }\end{array}$ & $\begin{array}{l}\text { Investigación } \\
\text { básica }\end{array}$ & $\begin{array}{c}\text { Investigación } \\
\text { aplicada }\end{array}$ & Extensión \\
\hline Estatal & D. público & Público (1) & Público (3) & Público (5) & Público (7) & Público (9) \\
\hline Estatal & D. privado & Público (11) & Público (13) & Público (15) & Público (17) & Público (19) \\
\hline No estatal & D. público & Público (21) & Público (23) & Público (25) & Público (27) & Público (29) \\
\hline No estatal & D. privado & Público (31) & Público (32) & Público (35) & Público (37) & Público (39) \\
\hline
\end{tabular}

Nota: El régimen jurídico es corporación de derecho público (D. público) y corporación de derecho privado (D. privado).

Los números entre paréntesis indican la combinación del diagrama de la Figura № 2 . 
b) Universidades docentes. Son aquellas que ofrecen esencialmente títulos profesionales, sin darle relevancia a investigación y desarrollo (I\&D). Ofrecen algo de extensión. Éstas pueden ser:

b.1) Universidades docentes públicas. Son aquellas que se concentran en ofrecer títulos y grados académicos esencialmente como bienes públicos. Pueden ofrecer bienes privados (véanse sus atributos en Tabla No 5 ).

\section{TABLA N ${ }^{\circ}$ 4: $\quad$ UNIVERSIDAD COMPLETA PRIVADA PURA}

\begin{tabular}{|c|c|c|c|c|c|c|}
\hline \multirow[b]{2}{*}{ Propiedad } & \multirow[b]{2}{*}{$\begin{array}{l}\text { Régimen } \\
\text { jurídico }\end{array}$} & \multicolumn{5}{|c|}{ Bienes económicos públicos o privados } \\
\hline & & $\begin{array}{c}\text { Título } \\
\text { profesional }\end{array}$ & $\begin{array}{c}\text { Grados } \\
\text { académicos }\end{array}$ & $\begin{array}{l}\text { Investigación } \\
\text { básica }\end{array}$ & $\begin{array}{c}\text { Investigación } \\
\text { aplicada }\end{array}$ & Extensión \\
\hline Estatal & D. público & Privado (2) & Privado (4) & Privado (6) & Privado (8) & Privado (10) \\
\hline Estatal & D. privado & Privado (12) & Privado (14) & Privado (16) & Privado (18) & Privado (20) \\
\hline No estatal & D. público & Privado (22) & Privado (24) & Privado (26) & Privado (28) & Privado (30) \\
\hline No estatal & D. privado & Privado (32) & Privado (34) & Privado (36) & Privado (38) & Privado (40) \\
\hline
\end{tabular}

Nota: El régimen jurídico es corporación de derecho público (D. Público) y corporación de derecho privado (D. Privado). Los números entre paréntesis indican la combinación del diagrama de la Figura $\mathrm{N}^{\circ} 2$.

TABLA N ${ }^{\circ}$ 5: $\quad$ UNIVERSIDAD DOCENTE

\begin{tabular}{|c|c|c|c|c|c|c|}
\hline & & & Tipo & de bien econón & nico & \\
\hline & & U. docent & e pública & U. docent & e privada & Además \\
\hline Propiedad & $\begin{array}{l}\text { Régimen } \\
\text { jurídico }\end{array}$ & $\begin{array}{c}\text { Título } \\
\text { profesional }\end{array}$ & $\begin{array}{c}\text { Grados } \\
\text { académicos }\end{array}$ & $\begin{array}{c}\text { Investigación } \\
\text { básica }\end{array}$ & $\begin{array}{c}\text { Investigación } \\
\text { aplicada }\end{array}$ & Extensión \\
\hline Estatal & D. público & Público (1) & Público (3) & Privado (6) & Privado (8) & Priv. o públ. \\
\hline Estatal & D. privado & Público (11) & Público (13) & Privado (16) & Privado (18) & Priv. o públ. \\
\hline No estatal & D. público & Público (21) & Público (23) & Privado (26) & Privado (28) & Priv. o públ. \\
\hline No estatal & D. privado & Público (31) & Público (33) & Privado (36) & Privado (38) & Priv. o públ. \\
\hline
\end{tabular}

Nota: El régimen jurídico es corporación de derecho público (D. público) y corporación de derecho privado (D. privado). Los números entre paréntesis indican la combinación del diagrama de la Figura $\mathrm{N}^{\circ} 2$.

* Esto indica que toda universidad docente, sea ésta pública o privada, debe ofrecer algo ya sea de investigación y desarrollo (I\&D) o algo de extensión, en un nivel inferior al ofrecido por las universidades completas, además de ofrecer títulos y grados académicos. 
b.2) Universidades docentes privadas. Son aquellas que ofrecen títulos y grados académicos esencialmente como bienes privados (véase Tabla $\mathrm{N}^{\mathrm{o}} 3$ ).

c) Universidades de investigación. Son aquellas que ofrecen principalmente productos asociados a investigación y desarrollo, sean bienes públicos o privados. En estricto rigor, estos organismos no son universidades propiamente tales sino que centros de investigación.

\section{Conclusiones}

En vista de la gran cantidad de definiciones utilizadas para clasificar a las universidades chilenas y dado lo peculiar del sistema chileno en relación con otros países, se necesita contar con una taxonomía de las universidades que permita identificar hacia dónde se quiere dirigir los recursos económicos del Estado. No se pueden destinar los recursos económicos en base únicamente a la estructura de propiedad ni sólo en base a la estructura jurídica de los planteles. Se requiere, además, establecer una relación con los productos y servicios que cada universidad ofrece a la comunidad. Se trata, entonces, de aplicar el tradicional enfoque de "insumo-producto" para medir la eficiencia económica y poder priorizar hacia dónde el Estado quiere destinar sus recursos.

A fin de determinar posibles fallas de mercado y establecer las regulaciones que deberían resolver esas fallas, otro aspecto que debe aclararse es el carácter de bien privado y bien público de los productos que ofrecen las universidades. Sin la claridad de una definición global respecto a las universidades y los bienes privados y públicos que ellas ofrecen, se hace difícil evaluar el funcionamiento del mercado en la educación superior chilena.

Del artículo se deduce que se pueden establecer tipologías de universidades considerando simultáneamente la propiedad, la organización jurídica y el tipo de bienes y servicios que la universidad ofrece. Esta tipología aúna criterios homogéneos y permite clarificar el cúmulo de definiciones en actual uso. 
A partir de estas definiciones se puede establecer qué recursos se destinan a las universidades en su conjunto, ya sea como aportes fiscales directos a la institución, así como aportes fiscales directamente hacia los productos que sean definidos como bienes públicos. Así, si una universidad es "completa y pública pura" debería tener pleno derecho a recibir aportes estatales por su sola función pública, además de los recursos que se reciban por los bienes públicos que ofrece a la comunidad.

\section{REFERENCIAS BIBLIOGRÁFICAS}

Alessandri R. Arturo, Somarriva R. Manuel y Vodanovic H. Antonio (2005). Tratado de Derecho Civil. Tomo I. Santiago: Editorial Jurídica de Chile, $7^{\mathrm{a}}$. edición.

Beyer, Harald (2009). "Nuevo Trato con las Estatales". Diario La Tercera, 18.1.2009, Santiago, Chile.

Brunner, José J. (1991). "Educación Superior en Chile. Fundamento de una Propuesta". Serie Educación y Cultura $\mathrm{N}^{\circ}$ 9, junio. Facultad Latinoamérica de Ciencias Sociales (FLACSO), Santiago, Chile.

Código Civil de República de Chile. (2007). Santiago: Editorial Jurídica de Chile.

Ducci C., Carlos (2007). Derecho Civil. Santiago: Editorial Jurídica de Chile, $4^{a}$ edición.

Krauskopf, Manuel (1992). "La Investigación Universitaria en Chile. Reflexiones Críticas". Corporación de Promoción Universitaria (CPU), Santiago, Chile.

Merino, Luis (2004). "El Sistema Universitario y la Vinculación Cultural con el Medio". Universidad y Sociedad, No 20, 1er. Semestre, Publicaciones CSE (Consejo Superior de Educación), Santiago.

Mönckeberg, María O. (2007). El Negocio de las Universidades en Chile. Santiago: Debate Edit.

Nicholson, Walter (2004). Teoría Microeconómica. Principios Básicos y Aplicaciones. International Thompson Editores, 8 a edición.

Organización para la Cooperación y el Desarrollo Económico (OCDE) (1981). "La Medición de las Actitudes Científicas y Técnicas”.

Organización para la Cooperación y el Desarrollo Económico (OCDE) (1981). "Manual de Frascati”, CDTI, Madrid, España.

Organización para la Cooperación y el Desarrollo Económico (OCDE), Banco Mundial, (2009). "La Educación Superior en Chile". Publicado por Ministerio de Educación de Chile, Santiago, Chile.

Samuelson, Paul y Nordhaus, W. (1996). Economía. McGraw-Hill/Interamericana, decimoquinta edición.

Zolezzi, Juan M. (2009). "Educación Superior Pública en Chile". Le Monde Diplomatique, edición chilena, Año IX, Nº 96, mayo, Santiago, Chile. 